\title{
Metformin - a Future Therapy for Neurodegenerative Diseases
}

\section{Theme: Drug Discovery, Development and Delivery in Alzheimer's Disease Guest Editor: Davide Brambilla}

\author{
Magdalena Markowicz-Piasecka ' (D) Joanna Sikora' • Aleksandra Szydłowska' • Agata Skupień ' E Elżbieta Mikiciuk-Olasik² • \\ Kristiina M. Huttunen ${ }^{3}$
}

Received: 4 May 2017 / Accepted: 30 May 2017 / Published online: 6 June 2017

(C) The Author(s) 2017. This article is an open access publication

\begin{abstract}
Type 2 diabetes mellitus (T2DM) is a complex, chronic and progressive metabolic disease, which is characterized by relative insulin deficiency, insulin resistance, and high glucose levels in blood. Esteemed published articles and epidemiological data exhibit an increased risk of developing Alzheimer's disease (AD) in diabetic pateints. Metformin is the most frequently used oral anti-diabetic drug, which apart from hypoglycaemic activity, improves serum lipid profiles, positively influences the process of haemostasis, and possesses anti-inflammatory properties. Recently, scientists have put their efforts in establishing metformin's role in the treatment of neurodegenerative diseases, such as $\mathrm{AD}$, amnestic mild cognitive impairment and Parkinson's disease. Results of several clinical studies confirm that long term use of metformin in
\end{abstract}

Magdalena Markowicz-Piasecka

magdalena.markowicz@umed.lodz.pl

Joanna Sikora

joanna.sikora@umed.lodz.pl

Aleksandra Szydłowska

aleksandra.szydlowska@o2.pl

Agata Skupień

agata.sk123@gmail.com

Elżbieta Mikiciuk-Olasik

elzbieta.mikiciuk-olasik@umed.lodz.pl

Kristiina M. Huttunen

kristiina.huttunen@uef.fi

Laboratory of Bioanalysis, Department of Pharmaceutical Chemistry

Drug Analysis and Radiopharmacy, Medical University of Lodz

Muszynskiego I, 90-I5I, Lodz, Poland

2 Department of Pharmaceutical Chemistry, Drug Analysis and Radiopharmacy, Medical University of Lodz ul., Muszyńskiego I, 90-I5I, Lodz, Poland

3 School Of Pharmacy, Faculty of Health Sciences, University of Eastern Finland, Yliopistonranta IC, POB I627, 702 II Kuopio, Finland diabetic patients contributes to better cognitive function, compared to participants using other anti-diabetic drugs. The exact mechanism of metformin's advantageous activity in $\mathrm{AD}$ is not fully understood, but scientists claim that activation of AMPK-dependent pathways in human neural stem cells might be responsible for the neuroprotective activity of metformin. Metformin was also found to markedly decease Betasecretase 1 (BACE1) protein expression and activity in cell culture models and in vivo, thereby reducing BACE1 cleavage products and the production of $\mathrm{A} \beta$ ( $\beta$-amyloid). Furthermore, there is also some evidence that metformin decreases the activity of acetylcholinesterase (AChE), which is responsible for the degradation of acetylcholine (Ach), a neurotransmitter involved in the process of learning and memory. In regard to the beneficial effects of metformin, its anti-inflammatory and antioxidative properties cannot be omitted. Numerous in vitro and in vivo studies have confirmed that metformin ameliorates oxidative damage.

KEY WORDS acetylcholinesterase · alzheimer's disease . metformin · neurodegeneration · oxidative stress

$\begin{array}{ll}\text { ABBREVIATIONS } \\ \text { A } & \beta \text {-amyloid } \\ \text { Abs } & \text { Acyl binding site } \\ \text { Ach } & \text { Acetylcholine } \\ \text { AchE } & \text { Acetylcholinesterase } \\ \text { AD } & \text { Alzheimer's disease } \\ \text { AGEs } & \text { Advanced glycosylation end products } \\ \text { Akt } & \text { Protein kinase B } \\ \text { AOPP } & \text { Advanced oxidation protein products } \\ \text { ApoE } & \text { Apolipoprotein E } \\ \text { APP } & \text { Amyloid } \beta \text { precursor protein } \\ \text { AS } & \text { Anionic substrate binding site } \\ \text { BACE } & \text { Beta-secretase } 1 \\ \text { BBB } & \text { Blood-brain barrier }\end{array}$




\begin{tabular}{|c|c|}
\hline Bcl-2 & B-cell lymphoma 2 \\
\hline BDNF & Brain-derived neurotrophic factor \\
\hline BuChE & Butyrylcholinesterase \\
\hline CAT & Catalase \\
\hline$C D$ & Cluster determinant \\
\hline CERB & CAMP Responsive Element Binding protein \\
\hline CGN & Cerebellar granule neurons \\
\hline ChE & Choline esterase \\
\hline $\operatorname{cox}$ & Cyclooxygenase \\
\hline CRP & C-reactive protein \\
\hline CVD & Gerebrovascular disease \\
\hline D-loop & Displacement loop \\
\hline eNOS & Nitric oxide synthase 3 \\
\hline RAP & Ferritin reducing ability of plasma \\
\hline GFAP & Glial fibrillary acidic protein \\
\hline GLP-I & Glucagon-like peptide-1 \\
\hline Grp78 & Glucose regulated protein 78 \\
\hline GSH & Reduced glutathione \\
\hline GSSG & Oxidised glutathione \\
\hline $\mathrm{HF}$ & High fat \\
\hline HFM & High-fat diet supplemented with metformin \\
\hline VCS's & Human neural stem cells \\
\hline hIAPP & Human islet amyloid polypeptide \\
\hline |ba- | & Ionized calcium binding adaptor molecule 1 \\
\hline $\mid \mathrm{L}-\mathrm{I}$ & Interleukin 1 \\
\hline LATI & L-type amino acid transporter 1 \\
\hline LCAT & Lecithin-cholesterol asyltransferase \\
\hline LPL & Lipoprotein lipase \\
\hline LTP & Long-term potentiation \\
\hline MDA & Malondialdehyde \\
\hline $\begin{array}{l}\text { MTP/NMTP } \\
\text { tasks }\end{array}$ & Matching and non-matching to position tasks \\
\hline NFTs & Neurofibrillary tangles \\
\hline NF-KB & $\begin{array}{l}\text { Nuclear factor kappa-light-chain-enhancer of } \\
\text { activated B cells }\end{array}$ \\
\hline NGF & Nerve growth factor \\
\hline 2F-I & Nitrogen Response Factor 1 \\
\hline rf 3 & Neurotrophin 3 \\
\hline $\mathrm{OAH}$ & Oxyanion hole \\
\hline p38 & Mitogen-activated protein kinase \\
\hline$p-1 k b$ & IkappaB proteins \\
\hline & Peripheral anionic binding site \\
\hline $\begin{array}{l}\text { PGC-I } \\
\text { alpha }\end{array}$ & $\begin{array}{l}\text { Transcriptional coactivator for steroid } \\
\text { receptors }\end{array}$ \\
\hline PKC & Protein kinase $\mathrm{C}$ \\
\hline $\mathrm{DN}$ & Paraoxonase \\
\hline AR- $Y$ & Peroxisome proliferator-activated receptors \\
\hline Z & Pentylenetetrazole \\
\hline AGEs & Receptor for advanced glycation endproducts \\
\hline VS & Reactive nitrogen species \\
\hline ROS & Reactive oxygen species \\
\hline & Spinal cord injury \\
\hline $\mathrm{Dm}$ & Type 2 diabetes mellitus \\
\hline
\end{tabular}

Tfam Transcription Factor A Mitochondrial

TNF- $\alpha \quad$ tumour necrosis factor $\alpha$

UPR Unfolded protein response

VEGF Vascular endothelial growth factor

\section{INTRODUCTION}

Type 2 diabetes mellitus (T2DM) is a common, complex, and progressive metabolic disease, which is characterized by 3 pathophysiologic anomalies: relative insulin deficiency, insulin resistance, and hepatic insulin resistance (resulting in increased gluconeogenesis and impaired glycogen synthesis) $(1,2)$. Importantly, the disease can lead to end-organ impairments in almost all vital organs, including the brain. According to the latest reports, cognitive decline and dementia are recognized and regarded as diabetes related complications $(3,4)$. The relation between diabetes and cognitive impairment may be associated with metabolic lesions that occur during diabetes (such as macrovascular and microvascular changes, impaired glucose metabolism, chronic inflammation, hyperinsulinemia, insulin resistance), increased cardiovascular and life style risk factors (3-5). All these changes may lead to functional disturbances in neurons, finally resulting in cell death (6).

Lifestyle interventions supported by one anti-diabetic drug prescription initiates conventional diabetes treatment. Several drug categories have been introduced to the pharmaceutical market for the treatment of T2DM. They are as follows: sulfonylureas, meglitinides, biguanides, inhibitors of $\alpha$-glucosidase, thiazolidinediones, dipeptidyl peptidase 4 inhibitors (gliptins), glucagon-like peptide-1 (GLP-1) analogues and amylin analogues (7-9). Generally, newly diagnosed patients suffering from T2DM are put on metformin monotherapy, which, in the case of insufficient glucose control, is then supplemented by other oral anti-diabetic drugs $(10,11)$.

Metformin does not only decrease the plasma glucose level in several mechanisms, but is also characterized to beneficially effect serum lipid profiles, reduce inflammatory cell adhesion to endothelium, and exert anti-inflammatory, anti-apoptotic and anti-oxidative properties $(12,13)$. For instance, it was found that metformin decreases interleukin $1 \beta$ (IL-1 $\beta$ ) induced activation of proinflammatory phosphokinases Akt (protein kinase B), p38 (mitogen-activated protein kinase) (14). Taking into consideration the basic mechanisms occurring in T2DM and brain disorders, anti-diabetic dugs such as metformin might also beneficially affect the metabolism of brain cells. These effects could be regarded as clinical important for the treatment of brain complications both in T2DM and neurological diseases. On the basis of reviewing scientific literature we can imply that there is a tendency towards the application of metformin in the treatment of Alzheimer's disease (AD) (15), amnestic mild cognitive impairment (16) and 
Parkinson's disease (17). However, the presumed mechanisms underlying the neuroprotective effects of metformin in various neurodegenerative disease models are still unknown (18). Therefore, we resolved to do literature review regarding possible mechanisms connecting T2DM with $\mathrm{AD}$ and discuss the emerging data with particular emphasis on potential of metformin towards amelioration of neurodegeneration and its neuroprotective properties. Recent scientific papers suggest that metformin may reduce the risk of $\mathrm{AD}$ by its ability to sensitize neuronal insulin resistance $(18,19)$. However, metformin was also found to increase the generation of amyloid beta $(\mathrm{A} \beta)$ protein (20), which, in turn, indicates that therapy with metformin may promote the development of $\mathrm{AD}(21)$.

On the basis of the presented results, and taking into account that T2DM increases the overall risk for the development of cognitive impairments and dementia, we decided to review the latest data on metformin application for the treatment of neurodegenerative diseases with particular emphasis on $\mathrm{AD}$.

\section{AD, T2DM AND METFROMIN}

$\mathrm{AD}$ is the most common neurodegenerative disease defined by progressive memory shortfall and neuronal loss. The pathological characteristics of $\mathrm{AD}$ are as follow: extracellular amyloid plaques consisting of aggregated $\mathrm{A} \beta$, intracellular neurofibrillary tangles (NFTs) comprising of hyperphosphorylated tau protein, and neuronal loss (22). A $\beta$ develops from consecutive cleavage of the amyloid $\beta$ precursor protein (APP) by $\beta$ site APP cleavage enzyme 1 (BACE1) and the $\gamma$-secretase complex (23,24). Additionally, numerous works have provided convincing evidence that $\mathrm{AD}$ might be regarded as a metabolic disease in which the brain becomes unable to efficiently utilize glucose for energy production and unable to respond to critical trophic factor signals due to insulin resistance (25).

The review of most recent papers and epidemiological data show an increased risk of developing $\mathrm{AD}$ in people with T2DM. For instance, Biessels et al. reported an increased risk of $\mathrm{AD}$ in diabetic patients (26). Kopf et al. also noted a heightened risk of $\mathrm{AD}$ in people with diabetes (27). There are also other studies indicating an elevated risk of developing $\mathrm{AD}$ in patients suffering from T2DM $(28,29)$. Zhang et al. published an updated meta-analysis of cohort studies on the risk of $\mathrm{AD}$ among diabetic patients. This work included 17 studies involving 1,746,777 individuals. The results of pooling these 17 studies showed subjects with diabetes had a significantly higher incidence of $\mathrm{AD}$ than those without this metabolic disease (RR: 1.53, 95\% CI: 1.42-1.63) (30).

Despite all the above-mentioned evidences linking diabetes and $\mathrm{AD}$, there are also arguments that diabetes does not predispose to $\mathrm{AD}$ (31). Some clinical studies have not confirmed the association between $\mathrm{AD}$ and diabetes (32,33), with the exception apolipoprotein $\mathrm{E}(\mathrm{ApoE}) \varepsilon 4$ allele carriers (28). ApoE, a cholesterol carrier in the brain and mediator of the uptake of lipoprotein, is coded by a gene which has three polymorphic alleles: $\varepsilon 2, \varepsilon 3$ and $\varepsilon 4$ (34). Among them, ApoE- $\varepsilon 4$ was identified as the strongest genetic risk factor for AD (34). Since 1996 it has been confirmed that homozygous ApoE- $\varepsilon 4$ are responsible for increasing the risk of $\mathrm{AD}$ by eight folds in Caucasians (35). In addition, patients with T2DM who carry the ApoE- $\varepsilon 4$ allele are two-fold more prone to develop AD than those without diabetes (28). Furthermore, it has been confirmed that mitochondrial damage is more severe in $\mathrm{AD}$ patients carrying ApoE- $\varepsilon 4$ compared with those carrying ApoE-ع3 (36).

In turn, one of the latest studies concluded that diabetes increases the risk of cerebrovascular, but not $\mathrm{AD}$, pathology (31). Studies often describe increased cerebrovascular pathology $(28,33)$. It is also worth to highlight that some studies have reported an increased risk of cerebrovascular disease (CVD) in people with T2DM (37). As far as we are concerned, the above-mentioned discrepancies may result from different definitions, types and severity of cognitive impairment, diverse ages of the study subjects, different comorbidities or lack of information about them and severity of the diabetes. Some authors claim (5) that the relationship between diabetes and cognitive decline in patients with $\mathrm{AD}$ has not yet been clearly established and highlight that more well-designed clinical studies are needed in order to clarify the effect of diabetes on cognitive function in patients with $\mathrm{AD}(5)$. Figure 1 presents a scheme summarizing the possible mechanisms linking diabetes and associated risk factors of dementia and ageing related brain changes.

Metformin, the drug which causes sensitization to insulin (ISD), apart from diabetes treatment, has also been introduced for the therapy of polycystic ovary syndrome (PCOS) (38). When describing potential beneficial effects of metformin its multidirectional influence on cardiovascular system cannot be omitted. The results of UKPDS trial showed that metformin significantly reduced (by $42 \%$ ) the diabetes-related death, and also all-cause mortality (by 36\%) (9,39). In one of the latest studies Mima et al. (40) described a clinical trial including 355 stroke patients with T2DM, and reported that administration of metformin in T2DM patients prior to stroke onset may be associated with reduced neurological severity and improved acute-phase therapy outcomes (40). The mechanisms of metformin action on cardiovascular system is not fully understood, but regarding heart muscle it has been proved that the drug promotes myocardial preconditioning, reduces cardiomyocytes apoptosis during ischemia, enhances the adaptation of cardiomyocytes metabolism during ischemia, and protects against the development of heart failure (41). Metformin was also found to prevent micro- and macrovascular complications of diabetes mellitus by improving vascular endothelial functions (14) in AMPK-dependent way. 
Fig. I Mechanisms linking diabetes (Type 2 Diabetes Mellitus (T2DM)) and dementia. Occurrence of T2DM, as well as obesity, hypelipidaemia and hypertension are associated with and increased risk of macro- and microvascular changes, hyperglycaemia and insulin resistance giving rise to dementia (adopted from ( | | 9 ))

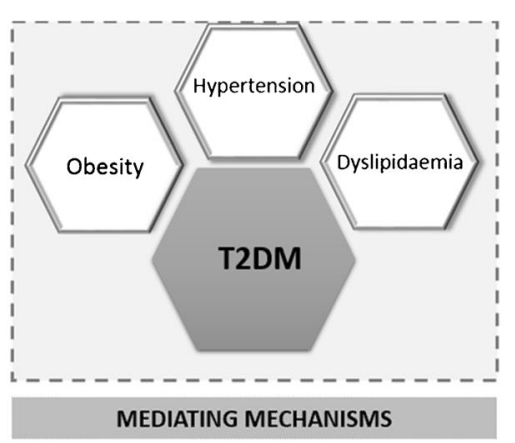

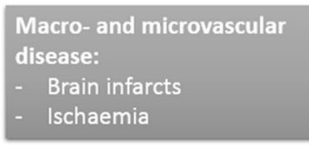

5
Hyperglycaemia:

- Advanced protein glycation Mitochondrial dysfunction Oxidative stress

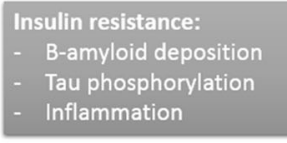

$\sqrt{3}$
Ladeiras-Lopes in his extensive review mentions that shortterm administration of metformin ameliorates endothelial dysfunction through increased availability of NO and improved endothelium-dependent vasodilatation (42). Additionally, the results of several experimental and clinical studies highlight the multidirectional effect of metformin on haemostasis, including platelets and plasma haemostasis with both coagulation and fibrinolysis system (9). For example metformin treatment is associated with improved atherothrombotic and inflammatory blood profile such as lowered levels of plasminogen activator inhibitor type 1, TNF- $\alpha$ and C-reactive protein (42). One issue that might also be of importance, is the fact that metformin may exert cancer chemopreventive effects by suppressing the transformative and hyper-proliferative processes. Metformin may also improve the efficacy of various chemotherapeutics and assist in overcoming the chemotherapy resistance $(43,44)$.

Regarding chemical structure, metformin is a biguanide (1,1-dimethylbiguanide hydrochloride) with highly hydrophilic properties which at physiological $\mathrm{pH}$ exists as cationic species $(45,46)$. Bioavailability of metformin after oral administration has been estimated at approximately $50-60 \%$, and the plasma half-life is $1.5-4 \mathrm{~h}$. Unfortunately, the bioavailability shows some intra-subject, as well as inter-subject variability (47). Concerning the distribution phase of metformin it should be mentioned in this point that the drug is not bound to plasma proteins (46). Metformin diffuses into erythrocytes, in a function of time. The most important pharmacokinetic parameters are as follows: the volume of distribution $(\mathrm{Vd})$ ranges from 63 to $276 \mathrm{~L}$ after intravenous administration, the apparent volume of distribution after oral administration $(\mathrm{Vd} / \mathrm{F})$ of $2000 \mathrm{mg}$ of metformin daily is approximately $600 \mathrm{~L}$ (46). In the case of metabolism and excretion phase it has been established that metformin is not metabolized (48), and approximately $30-50 \%$ of an oral dose is excreted in the urine as unchanged drug within $24 \mathrm{~h}$, and $30 \%$ of the dose is eliminated unchanged with the faeces (45). When describing the basic knowledge on metformin's pharmacokinetic it should be highlighted that metformin is a substrate for several organic cation transporters (OCTs 1-3), which determine its oral absorption, distribution, elimination (hepatic uptake, renal excretion) and, importantly, biochemical effects of metformin in humans (46).

The currently available literature on metformin's effects on the central nervous system and its potential role in AD treatment is limited and predominantly consists of in vitro studies and a few in vivo studies of short-term treatment in relatively young animals. There are also a few clinical studies attainable whose results will be discussed below.

Some studies give evidence that metformin might have beneficial effects on cognitive impairment and memory loss, while others show that metformin may be deleterious to neuronal survival. For instance, Zhao et al. (49) evaluated the ameliorative effects of metformin on seizures, cognitive impairment and brain oxidative stress markers observed in pentylenetetrazole-induced kindling animals. The authors confirmed that metformin suppressed the progression of kindling, ameliorated the cognitive impairment and decreased brain oxidative stress. These results led to the conclusion that metformin may be a potential preventive agent against cognitive impairment (49). Similarly, in the chronic L-methionine model of memory impairment, metformin was shown to prevent cognitive damage probably by normalizing oxidative stress in the hippocampus (50). In another study, it was shown that metformin prevents impairment of spatial reference memory associated with high fat diets in rats (51). These results were also confirmed by Ashrostaghi (52), who showed that in old rats orally administered metformin for 36 days 
showed a positive influence on the spatial memory performance in the Morris water maze.

According to Chen et al. (53), a 6 week treatment of metformin significantly ameliorates mice memory impairment, including the recovery of long-term potentiation (LTP) and normalization of several brain molecular alterations such as receptor for advanced glycation endproducts (RAGE) and nuclear factor kappa-light-chain-enhancer of activated B cells (NF-KB). In another study, McNeilly (54) investigated whether metformin treatment could diminish cognitive deficit evoked by the HF diet by improving insulin sensitivity. It was found that the drug attenuated the insulin resistance and weight gain associated with $\mathrm{HF}$ feeding, but had no effect on performance in operant-based matching and non-matching to position tasks (MTP/NMTP tasks) (54). Similarly, metformin treated to high fat fed mice displayed no significant effects on recognition memory in studies conducted by Lennox (55). Zhou et al. (56) published a study confirming metformin protective effects against cognitive deficits associated with the anti-cancer drug, cisplatin.

In the most recent study (51), Allard et al. examined the effect of long-term metformin administration on brain neurotrophins and cognition in aged male $\mathrm{C} 57 \mathrm{Bl} / 6$ mice. The authors divided animals into three groups: control $(\mathrm{C})$, high-fat $(\mathrm{HF})$ diet and a high-fat diet supplemented with metformin (HFM). It was reported that metformin prevented impairment of spatial reference memory associated with the HF diet. The analysis of brain homogenates showed a decreased transcription of BDNF (brain-derived neurotrophic factor), NGF (nerve growth factor) and neurotrophin 3 (Nrf 3), but protein levels were not altered. Metformin was also reported to decrease expression of the antioxidant pathway regulator, Nrf2. This study reveals the need for further investigation on the long-term treatment of metformin and its potential role in altering brain biochemistry $(51)$.

The results of some clinical studies show that long-term treatment with metformin could decrease the risk of cognitive decline (57). In addition, $\mathrm{Ng}$ et al. found no significant interactive effects of metformin use with APOE- $\varepsilon 4$ and depression (57). Also in a study of Guo et al. (58), it was confirmed that a 24-week intervention with metformin improved cognitive performance in depressed patients with T2DM. Additionally, as the authors highlighted, metformin significantly improved depressive performance and changed the glucose metabolism in depressed patients with diabetes (58). Another clinical study (59) examining the effect of diabetes treatment on specific cognitive domains over 4 years, showed that only participants who used metformin alone had better cognitive function (verbal learning, working memory, and executive functions) compared to participants who used other anti-diabetic drugs (59).

On the contrary, Moore et al. (60) in 2013 stated that the metformin effects on cognitive performance in patients might be influenced by its dependency on vitamin $\mathrm{B}_{12}$ deficiency, which is widely accepted as a major cause of cognitive decline. The authors implied that vitamin $\mathrm{B}_{12}$ and calcium supplements may alleviate metformin-induced vitamin $B_{12}$ deficiency (60). However, the recent study of Khattar et al. (61) showed that although the vitamin $B_{12}$ levels were deficient in diabetics on metformin, this was not the reason behind the cognitive impairment.

\section{POTENTIAL MECHANISMS OF METFORMIN ACTION IN AD}

\section{The Role of AMPK Linking Metformin with $\beta$-Amyloid Formation}

Chiti and Dobson (62) reported that the generation of amyloid peptides and aggregation of abnormally folded proteins are shared pathological characteristics in diabetes and $\mathrm{AD}$ (62). $\mathrm{A} \beta$, the major protein component of amyloid plaques, can oligomerize into larger soluble assemblies, but it can also undergo conformational changes and arrange into cross- $\beta$-sheet units, forming amyloid fibrils in the senile plaques (24). Generally, it has been accepted that fibrillar $\mathrm{A} \beta$ are responsible for the neurotoxicity, however, a stream of research has demonstrated the significance of soluble $A \beta$ assemblies in neuronal death $(63,64)$.

According to Clark et al. (65), 90\% of patients with T2DM have pancreatic islet amyloids, which are analogous to amyloid plaques in $\mathrm{AD}$ brains. The formation of these islet amyloids is associated with decreased $\beta$-cell mass (65). Luca et al. (66) showed that the molecular structure and morphology of human islet amyloid polypeptide (hIAPP) in the pancreas are similar to $\mathrm{A} \beta$ fibrils in $\mathrm{AD}$ (66). The exact functions of hIAPP are still unknown; however, studies conducted on mice models showed that the absence of hIAPP enhanced insulin secretion and improved glucose tolerance (67). Also in similar fashion, hIAPP oligomers were shown to cause $\beta$-cell death just like soluble $A \beta$ oligomers can lead to neuronal loss (68).

A number of studies confirm that metformin has a beneficial effect on human neural stem cells (69-71). Metformin is a drug that has an evidence based impact on neuroprotection via the activation of the AMPK pathway in human neural stem cells (hNCS's) (69). AMPK is widely known as a factor with a crucial role in the regulation of intracellular systems such as lipid metabolism, cellular glucose uptake or mitochondria biogenesis. Activation of AMPK-dependent pathways in human neural stem cells is a potential therapeutic target for $\mathrm{AD}$, because cellular mechanisms of energy homeostasis are connected to AD pathogenesis (69). In studies on hNSC's treated by A $\beta$, AMPK agonist (metformin) decreased cell viability and increased caspase 3/9 (a marker of caspase cascade activation) activity (69). Cells treated with $A \beta$ exhibited that $\mathrm{A} \beta$ also has an influence on the induction of apoptosis by 
disseminate cytochrome c (a major factor in the induction of an apoptosis which activates caspase 9), which is released from the mitochondria into the cytosol. Metformin significantly prevents this release. In the same study, it was shown that metformin increases transcript levels of B-cell lymphoma 2 (Bcl-2) and cAMP Responsive Element Binding protein (CERB), targets of AMPK, thereby enhancing AMPK expression (69). AMPK is also involved in neuroprotection via signaling pathways such as Gamma Coactivator-1 $\alpha$ (PGC1 $\alpha$ ), Nitrogen Response Factor 1 (NRF-1) and Transcription Factor A Mitochondrial (Tfam). The presence of A $\beta$ inhibits this neuroprotection involvement, which leads to a decrease in both the D-loop level and mitochondrial mass. Metformin rescues PGC1 $\alpha, \mathrm{NRF} 1$ and Tfam gene expression levels in hNSC. These genes were blocked by co-treatment with antagonist of AMPK (69).

The fact of the matter is that diabetes causes neurodegeneration by increased formation of advanced glycosylation end products (AGEs). AGEs are a group of molecules whose formation is initiated by a nonenzymatic reaction between sugars like glucose, and amino groups in proteins, lipids and nucleic acids (24). AGEs activate specific receptors for advanced glycation end-products (RAGE), which produce reactive oxygen species (ROS) and an inflammatory response (72). This interaction between the receptor and AGEs leads to an increase in the synthesis of the superoxide anion, which in turn reduces the activity of catalase and superoxide dismutase and simultaneously activates protein kinase C (72).

Several groups of scientists have proved that the formation and accumulation of AGEs is increased in subjects with T2DM and will determine the development of diabetic complications $(73,74)$. In the case of $\mathrm{AD}$, it has been found that AGEs colocalize with both neurofibrillary tangles and $\mathrm{A} \beta$ plaques, which contain three-fold higher AGEs levels in comparison with healthy controls (75). It has also been found that AGEs contribute to disease progression by accelerating the deposition of $\beta$-amyloid in different areas of the brain (76).

Accumulation of AGEs enhances hNSG cell death and mitochondrial dysfunction via downregulation of AMPK and its downstream signaling pathways. It should be mentioned here that mitochondria, and their dysfunction, have also been proposed as another fundamental link between $\mathrm{AD}$ and diabetes (24). In regard to diabetic patients, several abnormalities concerning mitochondria have been reported. They are as follows: increased intracellular calcium levels, deficiency in bioenergetic and antioxidant capacity, and changes in mitochondria morphology $(24,77)$. Taking into account AD and its associations with mitochondria dysfunction, it has been found that neurons rely heavily (about $90 \%$ of the ATP required for neuron functioning) on ATP synthesis by mitochondria; therefore, they are exceptionally prone to deteriorated mitochondrial functions $(78,79)$.
In research conducted by Chung, hNSCs were treated with AGEs and metformin. AGEs reduced cell viability and increased activity of caspase $3 / 9$, while the treatment with metformin normalized these two factors and prevented AGEs induced cytochrome c release from the mitochondria into the cytosol in the hNSCs (70). Metformin also had an impact on RAGE, which are vital in the pathogenesis of diabetic neurodegeneration. Metformin suppressed AGE- induced upregulation of RAGE mRNA levels in hNSGs. AGEs, just like $\mathrm{A} \beta$, participate in the release of cytochrome c from the mitochondria into the cytosol, which leads to apoptosis. In the mentioned studies it was shown that metformin prevents this action as well (70).

AMPK, which is activated through the phosphorylation at Thr-172, promotes diverse physiological signals that are involved in protective actions. In turn, metformin enhanced phosphorylation and weakened AGEs effects. For instance, AGEs decrease the levels of PGC1 $\alpha$, NRF1 and Tfam similarly to A $\beta$. Metformin, by activating AMPK, provides phosphorylation of the $\mathrm{PGC} 1 \alpha$ protein, which has the capacity to control NRF1 and Tfam transcription. Therefore, it contributes to the observed elevation in mitochondrial functions (71). The levels of ATP in AGE-treated hNSGs were lower than in vehicle controls; treatment with metformin restored ATP levels to normal. A similar situation occurred with Displacement loop (D-loop). AGEs also decreased hNSC mitochondrial mass by $60 \%$ compared to vehicle controls; treatment with metformin abrogated this effect. Maximal respiratory function, cyclooxygenase (COX) activity and mitochondrial membrane potential were decreased by exposure to AGEs, while metformin attenuated AGE induced reduction (70).

To survive, hNSGs need appropriate expression levels of peroxisome proliferator-activated receptors (PPAR- $\gamma$ ), Bcl-2, and CERB- genes that are targets of AMPK. Transcription of all three was significantly lowered in AGE- treated hNSC when compared to controls, but the addition of metformin reversed these effects. It should be highlighted that these effects of metformin treatment occurred in the absence of AMPK antagonist (70).

In studies conducted by DiTacchio (80), the hypothesis was that metformin treatment may provide protection against the development of AD. Scientists treated APP ( $\beta$-amyloid precursor protein) mice with metformin for up to one year and tested their cognitive function by the Morris water maze test. Surprisingly, the results revealed a gender-specific response in Alzheimer's phenotypes. Pharmacological activation of AMPK by metformin in male APP mice worsened learning and memory function. In contrast, female APP mice receiving the same treatment experienced improved learning and memory function. These findings raise the possibility that while metformin may enhance or replace part of a hormonal signaling pathway in females, it may counteract one in males (80). 
In another study, Hettich et al. (81) claimed that metformin markedly deceased BACE 1 protein expression and activity in cell culture models and in vivo, thereby reducing the BACE1 cleavage products and the production of $\mathrm{A} \beta$ (81). In turn, the next study evaluated the role of this antidiabetic drug in $A \beta$ transport across the blood-brain barrier (BBB) (53). Chen et al. treated type 2 diabetic male $d b / d b$ mice with metformin and other anti-diabetic drugs for 6 weeks and found that metformin significantly decreased the influx across the BBB via the RAGE expression and intra-arterial infusion of ${ }^{125} \mathrm{I}-\mathrm{A} \beta_{1-40}$ (53). In another in vivo experiment on the influence of metformin on mouse neuroblastoma cell lines, Neuro-2a (N2A) was assessed (19). The authors demonstrated that metformin markedly decreased $\mathrm{A} \beta$ levels under insulin resistant cell culture. Gupta and co-workers suggested that metformin ameliorates neuronal insulin resistance and AD-like changes (19). In 2012 Jiejie Li et al. claimed that metformin does not increase A $\beta 1-42$ accumulation in diabetic brains (82). Scientists in their experiments on mice discovered that high levels of A $\beta 1-42$ in the hippocampi of mice were attenuated by metformin (82).

In another study, Asadbegi et al. evaluated the neuroprotective influence of metformin on $A \beta$-induced disabilities in hippocampal synaptic plasticity in $\mathrm{AD}$ model rats fed a highfat (HF) (18). They treated A $\beta$-injected male Wistar rats with metformin and found that the drug decreased the effects of long-term potentiation (LTP) (18).

In the next study, Zhou et al. (83) demonstrated that pretreating rat cerebellar granule neurons (GGN) with metformin greatly enhanced cell viability against glutamateinduced neurotoxicity. Metformin significantly attenuated neuronal apoptosis in glutamate-treated CGN by reducing cytochrome c release, caspase-3 activation and phosphorylation of MAP kinases (83). In 2016 Niccoli et al. (84) decided to evaluate the effects of metformin on the unfolded protein response (UPR) negative master regulator expression. Authors demonstrated that genetic downregulation of Grp78 (glucose regulated protein) activity protected against $A \beta$ toxicity which is connected with $\mathrm{AD}$ pathogenesis. In their in vivo experiments on a Drosophila AD model, they noticed that metformin blocked the increase in Grp78 levels correlated with $A \beta$ expression (84).

Contrary to the above-mentioned articles, there are other studies which have shown that metformin may increase the risk of developing $\mathrm{AD}$ and be deleterious to neuronal survival through its AMPK activating mechanism $(20,85)$. For instance, studies conducted on mice treated with metformin for 6 days suggested that the drug exerts an effect on APP processing via activating the AMPK pathway. Researchers found that metformin treatment in a triple transgenic mouse model of $\mathrm{AD}$ led to an increase in the expression of $\beta$-secretase (BACE1), one of the two enzymes that cleave APP to generate $\mathrm{A} \beta$, which was accompanied by an increase in $\mathrm{A} \beta$ production and small plaque formation. The maximum effect of metformin was achieved in primary cultured neurons. This is a potential side-effect on accelerating $\mathrm{AD}$ pathogenesis and has to be taken into consideration when using metformin. In the same paper, it was also observed that metformin contributed to a decrease in $A \beta$ levels in a transgenic mouse line in longterm therapy which lasted 3 months. In the same study they confirmed that insulin decreased accumulation of $A \beta$ peptides (20).

Several other studies have suggested a link between chronic administration of metformin and accumulation of $\beta$-amyloid aggregates $(82,86,87)$. For example, in 2015 Picone and coworkers (86) established that metformin increases $A \beta$ metabolism and APP. In vitro, the authors explored that a higher concentration of metformin was associated with increased APP expression and consequently, the formation of A $\beta$ fragments and aggregates. Moreover, they indicated that the drug upregulates APP and presenilin 1 gene expression in the mouse brain. Scientists have suggested that the drug exerts a similar effect in vitro, ex viwo and in vivo (86).

Another report looking at the effects of AMPK activation in neuronal function, (85) found that metformin application reduced late long-term potentiation in hippocampal slices, an electrophysiological correlation to memory. These studies predict that metformin treatment might be harmful to patients suffering from $\mathrm{AD}$ by worsening their memory function (85). One of the most recent studies showed that metformin promoted processing and aggregation of $\mathrm{A} \beta$, mainly in the cortex region (87). The authors treated C57B6/J mice with metformin for seven days or three months; they noted that the drug stimulated APP processing especially in chronic administration. Futhermore, they found that metformin also increased the accumulation of $A \beta$ aggregates in the brain cortex region. In contrast, they did not observe the presence of $\mathrm{A} \beta$ aggregates in the hippocampus. Scientists have confirmed that metformin directly interacts with $A \beta$ peptide influencing its aggregation kinetics in vitro. According to the authors, this anti-diabetic drug induced molecular mechanisms leading to neurodegeneration in mice brains (87).

\section{Metformin as an AChE Inhibitor}

Acetylcholinesterase (AChE) is a type of cholinesterase enzyme responsible for hydrolysis of Acetylcholine (ACh). AChE divides ACh into acetate and choline in order to avoid its accumulation, which could lead to repeated and uncontrolled muscle stimulation (88). This enzyme is homodimer and has a three-dimensional structure and ellipsoidal shape (89). The enzymic hallmark of AChE is its active-site gorge, which lengthens $20 \AA$ into the protein and is lined with the rings of 14 highly conserved aromatic amino acids. AChE owns an active site which contains the following: (1) an esteratic site (ES) comprising of the catalytic triad Ser200- 
His440-Glu327, which is located at the bottom of the gorge; (2) an oxyanion hole $(\mathrm{OAH})$ that stabilizes the tetrahedral intermediate binding of the carbamate carbonyl group; (3) an acyl binding site (ABS) that binds the acetyl group of ACh or the alkyl moiety of carbamate inhibitors; (4) an anionic substrate binding site (AS) that contains a small number of negative charges but many aromatic residues (90). Another typical site called the "peripheral anionic binding site" (PAS) is situated in the peripheral part of the gorge and is comprised of Trp86, Tyr337, Trp286 and Tyr72 (90).

AChE can exist in several different molecular forms that have specific patterns of expression in various cell types (91). The primary forms in the healthy adult brain are tetramers $\left(\mathrm{G}_{4}\right)$, that are anchored in the cell membrane of neurons but also subsisting minor species, monomers $\left(\mathrm{G}_{1}\right)$ and dimers $\left(\mathrm{G}_{2}\right)$. In 1992 Arendt et al. published a paper in which they examined changes in particular species of AChE in AD; they observed a significant decrease in the $\mathrm{G}_{4}$ form and an incresase in the $\mathrm{G}_{1}$ form in the AD brain (92).

Garcia-Ayllon et al. (91) in their review indicated the potential participation of $\mathrm{AChE}$ in vicious cycles involving $\mathrm{A} \beta$ and P-tau. As presented by Gracia-Allon et al. several authors have suggested that P-tau can trigger an increase in AChE expression. In addition, it was also noticed that in the brains of a transgenic mice model with P-tau over-expression, all molecular forms of $\mathrm{AChE}$, including $\mathrm{G}_{4}$, were increased, contrarily to $A \beta$ transgenic models in which only one species of AChE was increased (91).

There are several in vivo studies evaluating the effect of metformin on AChE activity. For instance, Bhutada et al. (93) tested the influence of berberine, an isoquinolone alkaloid, and metformin against cognitive dysfunction in streptozotocin-induced diabetic rats. The authors assessed lipid peroxidation and glutathione levels as parameters of oxidative stress and choline esterase (ChE) activity as a marker of cholinergic function. Induction of diabetes in rats contributed to a severe impairment in learning and memory associated with increased lipid peroxidation and ChE activity. In was found that chronic treatment (30 days) of metformin at a dose of $500 \mathrm{mg} / \mathrm{kg}$ improved cognitive performance and reduced oxidative stress and ChE activity. No statistically significant effect on ChE activity was noted in short-term administration of metformin (5 days) (93). In another study, Saliu et al. confirmed that metformin at a dose of $500 \mathrm{mg} / \mathrm{kg}$ significantly decreased AChE activity in the brain of streptozocin-induced diabetic rats (94). Therefore, we may presume that inhibitory effects of metformin on this key enzyme linked with neurodegeneration may be responsible in preventing cholinergic dysfunction in T2DM.

On the contrary, there are also studies which do not report anti-ChE activity of metformin. For example, Arafa et al. (95) examined the effect of the antidiabetic medications, canagliflozin and metformin, on the levels of cortical neurotransmitters and $\mathrm{ChE}$ activity in a diabetic rat model (95). The authors reported that the diabetic group exhibited a significant increase in AChE activity and a decrease in monoamine and amino acid neurotransmitter levels. Two weeks of treatment with canagliflozin led to decreased AChE activity, whereas treatment with metformin showed no significant influence on the enzyme activity (95).

In another in vivo experiment, the authors assessed the influence of metformin on a scopolamine-induced memory deficit model (96). Authors treated adult male Wistar rats with metformin in various doses $(100 \mathrm{mg} / \mathrm{kg}$ and $300 \mathrm{mg} / \mathrm{kg}$ ) and they found a dose-related effect of metformin on memory performance. The lower dose of metformin $(100 \mathrm{mg} / \mathrm{kg})$ was found to ameliorate scopolamine-induced impairments via restoring the elevated total Akt and phosphorylated tau, and enhancing phosphorylated Akt levels in the hippocampus and cortex. However, the use of metformin at both doses was not associated with the reduction of tissue AChE activity (96). The reason for such ambiguous effects in the above-mentioned studies might be the different metformin doses administered to the animals.

Apart from AChE, another enzyme, butyrylcholinesterase, was found to be a common factor in the pathogenesis of both $\mathrm{AD}$ and T2DM. For instance, BuChE levels were shown to be altered in T2DM patients (97), and additionally, a correlation of BuChE with insulin sensitivity has been found (98). In the case of $\mathrm{AD}$, it has been found that BuChE attenuates amyloid fibril formation (99); associations of the enzyme with neurofibrillary tangles and amyloid plaques have also been found (100). According to Raygani et al. BuChE may modify the risk of $\mathrm{AD}$ alone, or in synergy with ApoE- $\varepsilon 4$ (101). However, no scientific reports on metformin effects on the activity or level of BuChE are available.

\section{Metformin as an Antioxidant}

The results of many studies have proved that oxidative stress, and consequently, increased levels of its markers such as oxidised lipids and proteins, play a major role in AD pathogenesis. These changes are thought to occur in the early stages of disease development $(102,103)$. According to Chen and Zhong the oxidation of proteins is related to diminished cerebral glucose metabolism in $\mathrm{AD}$, which in turn lead to disturbances in glucose homeostasis and neuronal impairment (104). Apelt et al. (105) reported that an increase in reactive nitrogen species (RNS) is associated with $\mathrm{A} \beta$ deposition in animal model studies. The other studies have documented that $\mathrm{A} \beta$ may interact with mitochondrial proteins, and later on, disrupt the electron transport chain, promote mitochondria dysfunction and the generation of ROS (106). It has also been reported that oxidative stress may enhance tau hyperphosphorylation (107). 
Similar oxidative changes, such as increased levels of protein oxidation, deficits in antioxidant defences enzymes and vitamins, a lower ratio of reduced glutathione to oxidised glutathione (GSH/GSSG ratio) and increased lipid peroxidation, have also been found in diabetes patients $(78,108)$. These processes were found to mediate diabetic neuropathy (109). It has also been found that insulin resistance occurring in $\mathrm{AD}$ correlates with elevated oxidative stress and DNA damage (110) (Fig. 2).

Apart from oxidative stress, inflammatory processes form a major part in the pathogenesis of T2DM, as well as AD (78). For instance, data from randomized clinical trials have shown that the development of T2DM is linked with increased levels of markers and mediators of inflammation, such as C-reactive protein (CRP) and interleukin 6 (IL-6) (111). In the case of $\mathrm{AD}$, it has been proven that the degree of chronic inflammation correlates with cognitive decline (112) and brain atrophy (113). According to Bruunsgaard et al. (114), AD predisposes to higher levels of tumour necrosis factor $\alpha(\mathrm{TNF}-\alpha)$, which is a pro-inflammatory cytokine. Additionally, higher concentrations of TNF- $\alpha$ were positively correlated with the concentrations of IL-6 and CRP (114).

Studies assessing the effects of metformin treatment on oxidative stress, as well as its anti-inflammatory response, have been recently reported. For instance, in studies conducted by Ran-ran Zhao (115) it was investigated whether metformin can suppress the progression of pentylenetetrazole (PTZ)-induced oxidative stress, which develops into epileptic seizures. The studies were carried out on mice models. In the PTZ group, the level of malondialdehyde (MDA), an index of lipid peroxidation, was very high. Treatment with metformin ameliorated the oxidative damage, showing cognitive protection and anti-oxidative properties of metformin (115). In another in vivo study, treatment with metformin was found to reduce the expression of astrocyte and microglial markers (Glial fibrillary acidic protein (GFAP), Ionized calcium binding adaptor molecule 1 (Iba-1)) and inflammation markers (IkappaB proteins (p-IKB), interleukin 1 (IL-1) and vascular endothelial growth factor (VEGF)), while simultaneously enhancing $\mathrm{p}$ AMPK and nitric oxide synthase 3 (eNOS) levels and increasing neuronal survival. These results imply the antiinflammatory properties of metformin (116). Additionally, Dai et al. (117) evaluated the anti-oxidative potential of metformin in a mouse model with carbon tetrachloride $\left(\mathrm{CCl}_{4}\right)$ induced severe oxidative liver injuries. Treatment with metformin significantly attenuated $\mathrm{CCl}_{4}$-induced elevation of serum aminotransferases and hepatic histological abnormalities. Furthermore, it was found that metformin in a dose dependent manner enhanced the activity of catalase (CAT) and decreased $\mathrm{CCl}_{4}$-induced elevation of hepatic $\mathrm{H}_{2} \mathrm{O}_{2}$ levels (117). In turn, Ma et al. (118), in a rat model of painful diabetic neuropathy induced by streptozotocin, found that metformin decreased MDA and glycation end- products levels in blood, as well as increased superoxide dismutase activity, indicating the inhibitory effect of metformin against diabetes-induced oxidative stress. In the next animal study, Wang et al. (13) reported that metformin provided neuroprotection through enhancing autophagy and suppressing the inflammation and apoptosis after a spinal cord injury (SCI).

A number of studies (119-121) have proved that metformin's pro-survival effects have been ascribed to the decreased intracellular production of ROS and improved balance between pro-oxidants and anti-oxidants. Results in the research of Khallaghi (119) demonstrated that Phosphoinositide 3-Kinase/S6 Protein Kinase (P13K/S6 K) activity is restored during metformin induced protection. Data suggests that metformin may enhance cell survival in the case of oxidative stress through strengthening anti-oxidant systems, particularly Glutathione Peroxidase (GSH) and catalase (CAT) - major detoxifying agents which degrade superoxide and $\mathrm{H}_{2} \mathrm{O}_{2}$ (119). In Bonnefont-Rousselot studies (120), it was revealed that metformin is able to scavenge hydroxyl free radicals, but not superoxides or hydrogen peroxides. In turn, Batchuluun et al. (122) evaluated the effects of metformin on
Fig. 2 The role of insulin resistance in $\mathrm{AD}$ development (e.g. mitochondrial dysfunction, which contributed to neuronal death, and inflammatory process; glycosylated hemoglobin and consecutive impaired cognitive function, oxidative stress-induced $\beta$-amyloid and phosphorylated tau formations through advanced glycation end products; GSK3 $\beta$ - glycogen synthase kinase-3; involved in energy metabolism, promotes the hyperphosphorylation of tau (adopted from ( 120$)$ ).

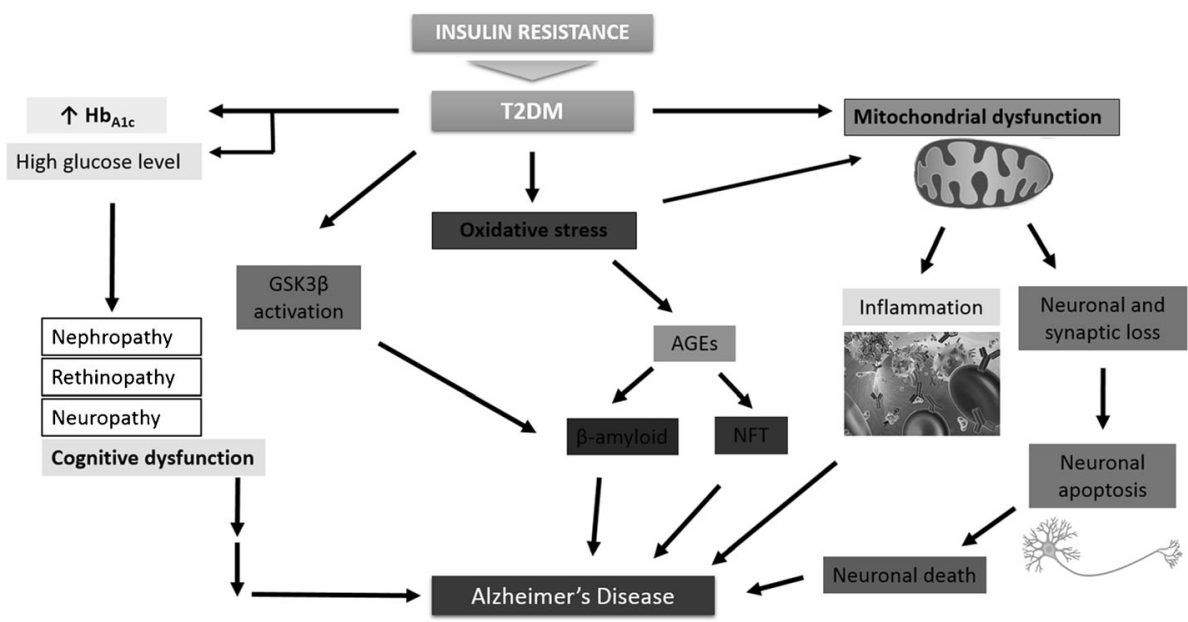


production of ROS, activation of protein kinase $\mathrm{C}(\mathrm{PKC})$ and $\mathrm{NAD}(\mathrm{P}) \mathrm{H}$ oxidase, and changes to signaling molecules in response to high glucose exposure in human aortic endothelial cells. The authors found that high glucose-induced ROS overproduction was blunted by metformin. In addition, metformin demonstrated protective effects against oxidative stress by inhibiting the PKC-NAD $(\mathrm{P}) \mathrm{H}$ oxidase pathway (122). In one of the most recent studies, Moon et al. (123) showed that metformin conferred protection against high glucose-induced apoptosis of pancreatic beta cells, mainly by interfering with ROS production and inhibiting CD36-mediated (cluster determinant 36) free fatty acid influx (123).

There are also a few clinical studies confirming metformin's beneficial anti-oxidative properties. For example, Esteghamati (124) investigated whether the use of metformin is more effective in reducing oxidative stress compared to lifestyle modification alone. Exploration was conducted on patients diagnosed with T2DM. Advanced oxidation protein products (AOPP) and advanced glycation end products (AGEs) were measured as markers of oxidative stress. Ferritin reducing ability of plasma (FRAP) was measured to represent inherent antioxidant capacity of plasma. The results revealed that lifestyle modifications with addition of metformin treatment compared to lifestyle changes alone, caused a significant reduction in AOPP and AGE and restoration of antioxidant support assessed by FRAP. Moreover, treatment with metformin demonstrated that the drug is involved in the protection of serum lipids (especially LDL) against oxidation (124). In another clinical trial, Mirmiranpour elucidated the effects of pioglitazone on oxidative stress modulation and compared its effects with metformin (125). Newly diagnosed T2DM patients were assigned to treatment with pioglitazone (30 mg daily), metformin (1000 mg daily), or no medication. Recommendations for exercise and dietary modifications were provided in all three groups. Both anti-diabetic medications provided influential benefits on the markers of oxidative stress in patients with diabetes. The drugs effectively decreased AOPP and AGE and increased enzymatic activities of paraoxonase (PON). In addition, some differences between the drugs were found, eg. FRAP concentrations increased significantly with metformin. On the other hand, pioglitazone exhibited better efficacy in restoration of lecithin-cholesterol asyltransferase (LCAT) and lipoprotein lipase (LPL) enzymatic activities (125). The next clinical study aimed to evaluate the effect of metformin on different stress and inflammatory parameters in T2DM subjects (126). The authors reported that ROS generation, advanced oxidation protein products, and pentosidine were reduced by metformin treatment compared to placebo. However, it was also found that metformin enhanced total thiol and nitric oxide levels. Metformin also contributed to significant restoration of CRP. Taken together, the authors concluded that metformin therapy improves the status of oxidative and nitrosative stress altered in T2DM (126).
Bułdak et al. (127) evaluated the impact of metformin on oxidative stress markers, antioxidative properties, inflammatory cytokines and phenotypical markers of human macrophages. The results of these experiments revealed that macrophages treated with metformin expressed less ROS, due to increased antioxidative potential. A reduction in inflammatory cytokines was also observed (127).

\section{Concluding Remarks and Future Prospects}

Metformin, the most frequently administered anti-diabetic drug, exerts a favourable effect on body weight, lipids, and cardiovascular risk associated with T2DM. Furthermore, the review of the most recent articles indicates that metformin might also be used in the treatment of polycystic ovarian syndrome, diabetic nephropathy and metabolic syndrome. There are also some studies identifying anti-cancer and anti-ageing properties of this biguanide.

Current available evidence suggests that metformin may play an important role in the treatment of $\mathrm{AD}$, as there are clinical studies confirming its beneficial effects regarding cognitive impairment and memory loss. Some authors also point out the advantageous activity of metformin on cognitive performance in depressed patients with T2DM. These favourable properties of metformin might stem from its molecular mechanism of action. For instance, the activation of AMPK by metformin has a neuroprotective effect on human neural stem cells, restores mitochondrial functions and weakens AGEs effects (70). Herein, we should also highlight the inhibitory properties of metformin on AChE, whose levels are elevated both in $\mathrm{AD}$ and T2DM. The results of esteemed scientific papers point out that the potential spectrum of metformin's beneficial effects also includes anti-inflammatory and anti-oxidative properties. In various types of in vitro and in vivo studies, it has been shown that metformin ameliorates oxidative damage.

On the basis of the presented results, we can imply that metformin exerts multi-directional effects regarding AD; however, there are also some ambiguous results that make further well designed, multicentre placebo controlled and randomised clinical studies necessary.

Metfromin rapidly crosses the BBB once in circulation and distributes well into several brain regions (128). It has also been demonstrated that lipopolysaccharide (LPS)- induced inflammation in the brain does not affect metformin's accumulation in distinct brain regions. Therefore, metformin seems to be a promising drug candidate for neurodegenerative disorders that are characterized by inflammation and oxidative stress. However, as the exact mechanisms of action of metformin are not fully understood, it is also unsure what levels of metformin are needed in which brain regions. Furthermore, the bioavailability, after oral administration, of metformin is poor (ca. 40-60\%); therefore, prodrug approaches have been applied to improve its oral absorption 
(129-133). For example, increasing the lipophilic character of metformin and subsequently passive permeation across the cell membranes has been attempted. However, this is not a feasible approach to improve the uptake across the BBB. Instead, in the future the prodrug should be developed to utilize specific transporters expressed in the BBB, such as Ltype amino acid transporter 1 (LAT1), to improve the brain uptake of metformin. In addition, the release of metformin from the lipophilic prodrugs has occurred rapidly in plasma. To reach the brain regions, the future prodrugs need to be more stable in systemic circulation and release metformin only after crossing the BBB by brain-specific enzymes.

In summary, metformin with its multi-directional properties, and safety and pharmacokinetic profile, is a promising candidate to prevent not only AD but also other neurodegenerative diseases; however, further drug development studies are worthwhile to achieve such successes.

\section{ACKNOWLEDGEMENTS AND DISCLOSURES}

The work is funded by National Science Centre in Poland (research project No. 2016/21/D/NZ7/01548), and by the Academy of Finland (grants 294227, 307057).

Open Access This article is distributed under the terms of the Creative Commons Attribution 4.0 International License (http://creativecommons.org/licenses/by/4.0/), which permits unrestricted use, distribution, and reproduction in any medium, provided you give appropriate credit to the original author(s) and the source, provide a link to the Creative Commons license, and indicate if changes were made.

\section{REFERENCES}

1. Setter SM, Iltz JL, Thams J, Campbell RK. Metformin hydrochloride in the treatment of type 2 diabetes mellitus: a clinical review with a focus on dual therapy. Clin Ther. 2003;25:29913026.

2. Zhang Z, Fang P, Shia M, Zhu Y, Bo P. Elevated galanin may predict the risk of type 2 diabetes mellitus for development of Alzheimer's disease. Mech Ageing dev. 2015;150:20-6.

3. Ascher-Svanum H, Chen YF, Hake A, Kahle-Wrobleski K, Schuster D, Kendall D, et al. Cognitive and functional decline in patients with mild Alzheimer dementia with or without comorbid diabetes. Clin Ther. 2015;37(6):1 195-205.

4. Banks WA, Owen JB, Erickson MA. Insulin in the brain: there and back again. Pharm Ther. 2012;136(1):82-93.

5. LiJ, Cesari M, Liu F, Dong B, Vellas B. Effects of diabetes mellitus on cognitive decline in patients with Alzheimer disease: a systematic review. Can J Diabetes. 2016:1-6.

6. Patrone C, Eriksson O, Lindholm D. Diabetes drugs and neurological disorders: new views and therapeutic possibilities. Lancet Diabetes Endocrinol. 2014;2(3):256-62.

7. Bashmakov YK, Petyaev IM. Old drug acquires new target: metformin and Sirt1. J Diabetes Metab. 2011;2:107.
8. Rizos CV, Elisaf MS. Metformin and cancer. Eur J Pharm. 2013;705:96-108.

9. Markowicz-Piasecka M, Huttunen KM, Mateusiak Ł, MikiciukOlasik E, Sikora J. Is metformin a perfect drug? Updates in pharmacokinetics and pharmacodynamics. Curr Pharm Design. 2017;23:1-19.

10. Mazzaglia G, Yurgin N, Boye KS, Trifiro G, Cottrell S, Allene E, et al. Prevalence and antihyperglycemic prescribing trends for patients with type 2 diabetes in Italy: a 4-year retrospective study from national primary care data. Pharm res. 2008;57:358-63.

11. Baviera M, Monesi L, Marzona I, Avanzini F, Monesi G. Trends in drug prescriptions to diabetic patients from 2000 to 2008 in Italy's Lombardy region: a large population-based study. Diabetes res Clin PR. 201 1;93:123-30.

12. Mahmood K, Naeem M, Rahimnajjad NA. Metformin: the hidden chronicles of a magic drug. Eur J Int med. 2013;24(1):20-6.

13. Wang C, Liu C, Gao K, Zhao H, Zhou Z, Shen Z, et al. Metformin preconditioning provide neuroprotection through enhancement of autophagy and suppression of inflammation and apoptosis after spinal cord injury. Biochem Biophys res com. 2016;477:534-40.

14. Isoda K, Young JL, Zirlik A, MacFarlane LA, Tsuboi N, Gerdes N. Metformin inhibits proinflammatory responses and nuclear factor-kappaB in human vascular wall cells. Arterioscler Thromb Vasc Biol. 2006;26:611-7.

15. Luchsinger JA, Tang MX, Shea S, Mayeux R. Hyperinsulinemia and risk of Alzheimer disease. Neurology. 2004;63:1 187-92.

16. http://clinicaltrials.gov. [Accessed February 12, 2017].

17. Mendelsohn AR, Larrick JW. Rapamycin as an antiaging therapeutic? Targeting mammalian target of rapamycin to treat Hutchinson-Gilford progeria and neurodegenerative diseases. Rejuvenation res. 2011;14:437-41.

18. Asadbegia M, Yaghmaeia P, Salehib I, Ebrahim-Habibic A, Komaki A. Neuroprotective effects of metformin against A $\beta$ mediated inhibition of long-term potentiation in rats fed a highfat diet. Brain res Bull. 2016;121:178-85.

19. Gupta A, Bisht B, Dey CS. Peripheral insulin-sensitizer drug metformin ameliorates neuronal insulin resistance and Alzheimer'slike changes. Neuropharmacology. 2011;60:910-20.

20. Chen Y, Zhou K, Wang R, Liu Y, Kwak YD, Ma T, et al. Antidiabetic drug metformin (GlucophageR) increasesbiogenesis of Alzheimer's amyloid peptides via up-regulating BACE1transcription. Proc Natl Acad Sci U S a. 2009;106: 3907-12.

21. Imfeld P, Bodmer M, Jick SS, Meier CR. Metformin, other antidiabetic drugs, and risk of Alzheimer'sdisease: a population-based case-control study. J am Geriatr Soc. 2012;60:916-21.

22. Johnson GV, Stoothoff WH. Tau phosphorylation in neuronal cell function and dysfunction. J Cell Sci. 2004;117:5721-9.

23. Sun X, Bromley-Brits K, Song W. Regulation of beta-site APPcleaving enzyme 1 gene expression and its role in Alzheimer's disease. J Neurochem. 2012;120(Suppl. 1):62-70.

24. Yang Y, Song W. Molecular links between Alzheimer's disease and diabetes mellitus. Neuroscience. 2013;250:140-50.

25. dela Monte S. Type 3 diabetes is sporadic Alzheimer's disease: Mini-review. Eur. Neuropsychopharm. 2014;24:1954-60.

26. Biessels GJ, Staekenborg S, Brunner E, Brayne C, Scheltens P. Risk of dementia in diabetes mellitus: a systematic review. Lancet Neurol. 2006;5:64-74.

27. Kopf D, Frolich L. Risk of incident Alzheimer's disease in diabetic patients: a systematic review of prospective trials. J Alzheimers dis. 2009; 16:677-85.

28. Peila R, Rodriguez BL, Launer LJ. Type 2 diabetes, APOE gene, and the risk for dementia and related pathologies: the HonoluluAsia aging study. Diabetes. 2002;51(4):1256-62. 
29. Arvanitakis Z, Wilson RS, Bienias JL, Evans DA, Bennett DA. Diabetes mellitus and risk of Alzheimer disease and decline in cognitive function. Arch Neurol. 2004;61(5):661-6.

30. Zhang J, Chen C, Hua S, Liao H, Wang M, Xiong Y, et al. An updated meta-analysis of cohort studies: diabetes and risk of Alzheimer's disease. Diabetes res Clin Pract. 2017;124:41-7.

31. Abnera EL, Nelson PT, Kryscio RJ, Schmitt FA, Fardo DW, Woltjer RL, et al. Diabetes is associated with cerebrovascular but not Alzheimer's disease neuropathology. Alzheimers Dement. 2016;12:882-9.

32. Beeri MS, Silverman JM, Davis KL, Marin D, Grossman HZ, Schmeidler J. Type 2 diabetes is negatively associated with Alzheimer's disease neuropathology. J Gerontol a Biol Sci med Sci. 2005;60:471-5.

33. Sonnen JA, Larson EB, Brickell K, Crane PK, Woltjer R, Montine TJ. Different patterns of cerebral injury in dementia with or without diabetes. Arch Neurol. 2009;66:315-22.

34. Corder EH, Saunders AM, Strittmatter WJ, Schmechel DE, Gaskell PG, Small GW, et al. Gene dose of apolipoprotein E type 4 allele and the risk of Alzheimer's disease in late onset families. Science. 1993;261:921-3.

35. Roses AD. Apolipoprotein E alleles as risk factors in Alzheimer's disease. Annu rev med. 1996;47:387-400.

36. Gibson GE, Haroutunian V, Zhang H, Park LG, Shi Q, Lesser M, et al. Mitochondrial damage in Alzheimer's disease varies with apolipoprotein E genotype. Ann Neurol. 2000;48:297-303.

37. Brundel M, Reijmer YD, van Veluw SJ, Kujif HJ, Luijten PR, Kappelle LJ. Cerebral microvascular lesions on high-resolution 7 TeslaMRI in patients with type 2 diabetes. Diabetes. 2014;63: 3523-9.

38. Lashen H. Role of metformin in the management of polycystic ovary syndrome. Ther Adv Endocrinol Metab. 2010;1:117-28.

39. UK Prospective Diabetes Study (UKPDS) Group. Effect of intensive blood-glucose control with metformin on complications in overweight patients with type 2 diabetes (UKPDS 34). Lancet. 1998;352:854-65.

40. Mima Y, Kuwashiro T, Yasaka M, Tsurusaki Y, Nakamura A, Wakugawa $Y$, et al. Impact of metformin on the severity and outcomes of acute ischemic stroke in patients with type 2 diabetes mellitus. J Stroke Cerebrovasc dis. 2016;25(2):436-46.

41. Giannarelli R, Aragona M, Cappelli A. Reducing insulin resistance with metformin: the evidence today. Diabetes Metab. 2003;29:6528-35.

42. Ladeiras-Lopes R, Fontes-Carvalho R, Bettencourt N, Sampaio F, Gama V, Leite-Moreira A. A novel therapeutic targets of metformin: metabolic syndrome and cardiovascular disease. Expert Opin Ther Targets. 2015;19(7):869-77.

43. Dong L, Zhou Q, Zhang Z, Zhu Y, Duan T, Feng Y. Metformin sensitizes endometrial cancer cells to chemotherapy by repressing glyoxalase I expres- sion. J Obstet Gynaecol res. 2012;38:107785.

44. Hanna RK, Zhou C, Malloy KM, Sun L, Zhong Y, Gehrig PA, et al. Metformin potentiates the effects of paclitaxel in endometrial cancer cells through inhibition of cell proliferation and modulation of the mTOR pathway. Gynecol Oncol. 2012;125:458-69.

45. Riedmaier AE, Fisel P, Nies AT, Schaeffeler E, Schwab M. Metformin and cancer: from the old medicine cabinet to pharmacological pitfalls and prospects. Trends Pharm Sci. 2013;34:12635.

46. Graham GG, Punt J, Arora M, Day RO, Doogue MP. Clinical pharmacokinetics of metformin. Clin Pharmacokinet. 2011;50: 81-98.

47. Huttunen KM, Rautio J, Leppänena J, Vepsäläinen J, KeskiRahkonen P. Determination of metformin and its prodrugs in human and rat blood by hydrophilic interaction liquid chromatography. J Pharm Biomed Anal. 2009;50:469-74.
48. http://www.fda.gov/Drugs/DrugSafety/ucm493244.htm. Access 5.01.2016.

49. Zhao RR, Xu XC, Xu F, Zhang WL, Zhang WL, Liu LM, et al. Metformin protects against seizures, learning and memory impairments and oxidative damage induced by pentylenetetrazoleinduced kindling in mice. Biochem Biophys res Commun. 2014;448:414-7.

50. Alzoubi KH, Khabour OF, Al-Azzam SI, Tashtoush MH, Mhaidat NM. Metformin eased cognitive impairment induced by chronic L-methionine administration: potential role of oxidative stress. Curr Neuropharmacol. 2014;12:186-92.

51. Allard JS, Perez EJ, Fukui K, Carpenter P, Ingram DK, Cabo R. Prolonged metformin treatment leads to reduced transcription of Nrf2 and neurotrophic factors without cognitive impairment in older C57BL/6J mice. Behav Brain res. 2015;301:1-9.

52. Ashrostaghi Z, Ganji F, Sepehri H. Effect of metformin on the spatial memory in aged rats. Nat J Phys Pharm Pharmacol. 2015;5(5):416-21.

53. Chen F, Dong RR, Zhong KL, Ghosh A, Tang SS, Long Y, et al. Antidiabetic drugs restore abnormal transport of amyloid-beta across the blood-brain barrier and memory impairment in $\mathrm{db} /$ db mice. Neuropharmacology. 2016;101:123-36.

54. McNeilly AD, Williamson R, Balfour DJK, Stewart CA, Sutherland C. A high-fat-diet-induced cognitive deficit in rats that is not prevented by improving insulin sensitivity with metformin. Diabetologia. 2012;55:3061-70.

55. Lennox R, Porter DW, Flatt PR, Holscher C, Irwin N, Gault VA. Comparison of the independent and combined effects of subchronic therapy with metformin and a stable GLP-1 receptor agonist on cognitive function, hippocampal synaptic plasticity and metabolic control in high-fat fed mice. Neuropharmacology. 2014;86:22-30.

56. Zhou W, Kavelaars A, Heijnen CJ. Metformin prevents cisplatininduced cognitive impairment and brain damage in mice. PLoS One. 2016;11(3):e0151890.

57. Ng TP, Feng L, Yap KB, Lee TS, Tan CH, Winblad B. Longterm metformin usage and cognitive function among older adults with diabetes. J Alzheimer's Disease. 2016;41:61-8.

58. Guo M, Mi Y, Jiang QM, Xu JM, Tang YY, Tian G, et al. Metformin may produce antidepressant effects through improvement of cognitive function among depressed patients with diabetes mellitus. Glin Exp Pharm Phys. 2014;41:650-6.

59. Herath PM, Cherbuin N, Eramudugolla R, Anstey KJ. The Effect of Diabetes Medication on Cognitive Function: Evidence from the PATH Through Life Study. BioMed Res. Int. 2016; Article ID 7208429, doi.org/10.1155/2016/7208429.

60. Moore EM, Mander AG, Ames D, Kotowicz MA, Carne RP, Brodaty $\mathrm{H}$, et al. Increased risk of cognitive impairment in patients with diabetes is associated with metformin. Diabetes Care. 2013;36:2981-7.

61. Khattar D, Khaliq F, Vaney N, Madhu SV. Is metformin-induced vitamin $\mathrm{B} 12$ deficiency responsible for cognitive decline in type 2 diabetes? Indian J Psychol med. 2016;38:285-90.

62. Chiti F, Dobson GM. Protein misfolding, functional amyloid, and human disease. Annu rev Biochem. 2006;75:333-66.

63. Shankar GM, Li S, Mehta TH, Garcia-Munoz A, Shepardson $\mathrm{NE}$, Smith I, et al. Amyloid-beta protein dimers isolated directly from Alzheimer's brains impair synaptic plasticity and memory. Nat med. 2008;14:837-42.

64. Townsend M, Shankar GM, Mehta T, Walsh DM, Selkoe DJ. Effects of secreted oligomers of amyloid beta-protein on hippocampal synaptic plasticity: a potent role for trimers. J Physiol. 2006;572:477-92.

65. Clark A, Wells CA, Buley ID, Cruickshank JK, Vanhegan RI Matthews DR, et al. Islet amyloid, increased A-cells, reduced B- 
cells and exocrine fibrosis: quantitative changes in the pancreas in type 2 diabetes. Diabetes res. 1988;9:151-9.

66. Luca S, Yau WM, Leapman R, Tycko R. Peptide conformation and supramolecular organization in amylin fibrils: constraints from solid-state NMR. Biochemistry. 2007;46:13505-22.

67. Gebre-Medhin S, Mulder H, Pekny M, Westermark G, Tornell J, Westermark P, et al. Increased insulin secretion and glucose tolerance in mice lacking islet amyloid polypeptide (amylin). Biochem Biophys res Commun. 1998;250:271-7.

68. Konarkowska B, Aitken JF, Kistler J, Zhang S, Cooper GJ. The aggregation potential of human amylin determines its cytotoxicity towards islet beta-cells. FEBS j. 2006;273:3614-24.

69. Chiang MC, Cheng YC, Chen SJ, Yen CH, Huang RN. Metformin activation of AMPK-dependent pathways is neuroprotective in human neural stem cell agains amyloid-betainduced mitochodrial dysfunction. Exp Cell res. 2016;347:32231.

70. Chung MM, Chen YL, Pei D, Cheng YC, Sun B, Nicol CJ, et al. The neuroprotective role of metformin in advanced glycation end product treated human neural stem cells is AMPK-dependent. Bioch Bioph Acta. 1852;2015:720-31.

71. Scarpello JH, Howlett HC. Metformin therapy and clinical uses. Diab Vasc dis res. 2008;5(3):157-67.

72. Domínguez RO, Pagano MA, Marschoff ER, González SE, Repettod M, Serra JA. Alzheimer disease and cognitive impairment associated withdiabetes mellitus type 2: associations and a hypothesis. Neurologia. 2014;29(9):567-72.

73. Hammes HP, Alt A, Niwa T, Clausen JT, Bretzel RG, Brownlee $\mathrm{M}$, et al. Differential accumulation of advanced glycation end products in the course of diabetic retinopathy. Diabetologia. 1999;42:728-36.

74. Goh SY, Cooper ME. Clinical review: the role of advanced glycation end products in progression and complications of diabetes. J Clin Endocrinol Metab. 2008;93:1143-52.

75. Smith MA, Taneda S, Richey PL, Miyata S, Yan SD, Stern D, et al. Advanced Maillard reaction end products are associated with Alzheimer disease pathology. Proc. Natl. Acad. Sci. U s a. 1994;91:5710-4.

76. Rolo A, Palmeira C. Diabetes and mitocondrial function: roleof hyperglycemia and oxidative stress. Toxicol Appl Pharmacol. 2006;212:167-78.

77. Kelley DE, He J, Menshikova EV, Ritov VB. Dysfunction of mitochondria in human skeletal muscle in type 2 diabetes. Diabetes. 2002;51:2944-50.

78. Verdile G, Fuller S, Martins RN. The role of type 2 diabetes in neurodegeneration. Neurobiol dis. 2015;84:22-38.

79. Han XJ, Tomizawa K, Fujimura A, Ohmori I, Nishiki T, Matsushita M, et al. Regulation of mitochondrial dynamics and neurodegenerative diseases. Acta med Okayama. 2011;65:1-10.

80. DiTacchio K. The effect of AMPK activation on Alzheimer's-like symptoms in APP mice. UC San Diego Electronic Theses and Dissertations 2011; http://escholarship.org/uc/item/0rh8k3sg [access 2017.04.10].

81. Hettich MM, Mattes F, Ryan DP, Griesche N, Schroder S, Dorn $\mathrm{S}$, et al. The Anti-Diabetic Drug Metformin Reduces BACE1 Protein Level by Interfering with the MID1 Complex. Plos one. 2014;9:e-102420.

82. Li J, Deng J. Sheng., Zuo Z. Metformin attenuates Alzheimer's disease-like neuropathology in obese, leptin-resistant mice. Pharmacol. Biochem. Beh. 2012;101:564-74.

83. Zhou C, Sun R, Zhuang S, Sun C, Jiang Y, Cui Y, et al. Metformin prevents cerebellar granule neurons against glutamate-induced neurotoxicity. Brain res Bul. 2016;121:241-5.

84. Niccoli T, Cabecinha M, Tillmann A, Kerr F, Wong CT, Cardenes D, et al. Increased glucose transport into neurons rescues Aß toxicity in drosophila. Curr Biol. 2016;26:2291-300.
85. Potter WB, O'Riordan KJ, Barnett D, Osting SM, Wagoner M, Burger C, et al. Metabolic regulation of neuronal plasticity by the energy sensor AMPK. PLoS One. 2010;5(2):e8996.

86. Picone P, Nuzzo D, Caruana L, Messina E, Barea A, Vasto S, et al. Metformin increases APP expression and processing via oxidative stress, mitochondrial dysfunction and NF-KB activation: use of insulin to attenuate metformin's effects. Bioch Biophys Acta. 1853;2015:1046-59.

87. Picone P, Vilasi S, Librizzi F, Contardi M, Nuzzo D, Caruana L, et al. Biological and biophysics aspects of metformin-induced effects: cortex mitochondrial dysfunction and promotion of toxic amyloid pre-fibrillar aggregates. Aging. 2016;8:1718-20.

88. Acetylcholinesterase: A gorge-ous enzyme: Protein Data Bank in Europe; http://www.ebi.ac.uk/pdbe/quips?story=AChE [access 1.04.2017].

89. Sussman JL, Silman I. Acetylcholinesterase: structure and use as a model for specific cation-protein interactions. Curr Opinion Struct Biol. 1992;2:721-9.

90. Imramovsky A, Stepankova S, Vanco J, Pauk K, Monreal-FerrizJ, Vinsova J, et al. Acetylcholinesterase-inhibiting activity of Salicylanilide $\mathcal{N}$-Alkylcarbamates and their molecular docking. Molecules. 2012;17:10142-58.

91. Gracia-Ayllon MS, Small DH, Avila J, Saez-Valero J. Revisiting the role of acetylcholinesterase in Alzheimer's disease: cross-talk with P-tau and $\beta$-amyloid. Front Mol Neurosc. 201 1;4:1-9.

92. Arendt T, Bruckner MK. Perisomatic sprouts immunoreactive for nerve growth factor receptor and neurofibrillary degeneration affect different neuronal populations in the basal nucleus in patients with Alzheimer's disease. Neurosci Lett. 1992;14:63-6.

93. Bhutada P, Mundhada Y, Bansod K, Tawaria S, Patil S, Dixit P, et al. Protection of cholinergic and antioxidant system contributes to the effect of berberine ameliorating memory dysfunction in rat model of streptozotocin-induced diabetes. Beh Brain res. 201 1;220:30-41.

94. Saliua JA, Oboh G, Omojokun OS, Rochad J, Schetinger MR, Guterries J, et al. Effect of dietary supplementation of Padauk (Pterocarpus soyauxii) leaf on high fat diet/streptozotocin induced diabetes in rats' brain and platelets. Biomed Pharmacother. 2016;84:1194-201.

95. Arafa NMS, Marie MA, AlAzimi SA. Effect of canagliflozin and metformin on cortical neurotransmitters in a diabetic rat model. Chemico-Biol Interact. 2016;258:79-88.

96. Mostafa DK, Ismail CA, Ghareeb DA. Differential metformin dose-dependent effects on cognition in rats: role of Akt. Psychopharmacol. 2016;233:2513-24.

97. Sridhar GR, Nirmala G, Apparao A, Madhavi AS, Sreelatha S, Rani JS. Serum butyrylcholinesterase in type 2 diabetes mellitus: a biochemical and bioinformatics approach. Lipids Health dis. 2005; 4:18.

98. Abott CA, Mackness MI, Kumar S, Olukoga AO, Gordon C, Arrol S. Relationship between serum butyrylcholinesterase activity, hypertriglyceridemia and insulin sensitivity in diabetes mellitus. Clin Sci. 1993;85:7-81.

99. Greig NH, Utsuki T, Ingram DK, Wang Y, Pepeu G, Scall C. Selective butyrylcholinesterase inhibition elevated brain acetylcholine, augments learning and lowers Alzheimer beta-amyloid peptide in rodent. Proc Natl Acad Sci. 2005;102:17213-8.

100. Gomez-Rooms P, Bourse C. Ultrastructural localization of butyrylcholinesterase on neurofibrillay degeneration sites in the brains of aged and Alzheimer's disease patients. Brain res. 1994;640:1734.

101. Raygani AV, Zahrai M, Soltanzadeh A, Doosti M, Javadi E, Pourmotabbed T. Analysis of association between butyrylcholinesterase K variant and apolipoprotein E genotypes in Alzheimer's disease. Neurosci Lett. 2004;371:142-6. 
102. Butterfield DA, Poon HF, St Clair D, Keller JN, Pierce WM, Klein JB, et al. Redox proteomics identification of oxidatively modified hippocampal proteins in mild cognitive impairment: insights into the development of Alzheimer's disease. Neurobiol dis. 2006:22:223-32.

103. Nunomura A, Perry G, Aliev G, Hirai K, Takeda A, Balraj EK, et al. Oxidative damage is the earliest event in Alzheimer disease. J Neuropathol Exp Neurol. 2001;60:759-67.

104. Chen Z, Zhong C. Decoding Alzheimer's disease from perturbed cerebral glucose metabolism: implications for diagnostic and therapeutic strategies. Prog Neurobiol. 2013;108:21-43.

105. Apelt J, Bigl M, Wunderlich P, Schliebs R. Aging-related increase in oxidative stress correlates with developmental pattern of betasecretase activity and beta-amyloid plaque formation in transgenic Tg2576 mice with Alzheimer-like pathology. Int J dev Neurosci. 2004:22:475-84.

106. Reddy PH, Manczak M, Mao P, Calkins MJ, Reddy AP, Shirendeb U. Amyloid-beta and mitochondria in aging and Alzheimer's disease: implications for synaptic damage and cognitive decline. J Alzheimers dis. 2010;20(Suppl. 2):499-512.

107. Sultana R, Boyd-Kimball D, Poon HF, Cai J, Pierce WM, Klein $\mathrm{JB}$, et al. Oxidative modification and down-regulation of Pinl in Alzheimer's disease hippocampus: a redox proteomics analysis. Neurobiol Aging. 2006;27:918-25.

108. Calabrese V, Cornelius C, Leso V, Trovato-Salinaro A, Ventimiglia B, Cavallaro M, et al. Oxidative stress, glutathione status, sirtuin and cellular stress response in type 2 diabetes. Biochim Biophys Acta. 1822;2012:729-36.

109. Russell JW, Berent-Spillson A, Vincent AM, Freimann CL, Sullivan KA, Feldman EL. Oxidative injury and neuropathy in diabetes and impaired glucose tolerance. Neurobiol dis. 2008;30: 420-9.

110. Butterfield DA, Di Domenico F, Barone E. Elevated risk of type 2 diabetes for development of Alzheimer disease: a key role for oxidative stress in brain. Biochim Biophys Acta. 1842;2014:1693706.

111. Pradhan AD, Manson JE, Rifai N, Buring JE, Ridker PM. Creactive protein, interleukin 6 , and risk of developing type 2 diabetes mellitus. Jama. 2001;286:327-34.

112. Parachikova A, Agadjanyan MG, Cribbs DH, Blurton-Jones M, Perreau V, Rogers J, et al. Inflammatory changes parallel the early stages of Alzheimer disease. Neurobiol Aging. 2007;28:1821-33.

113. Gagnin A, Gerhard A, Banati RB. In vivo imaging of neuroinflammation. Eur Neuropsychopharmacol. 2002;12:581-6.

114. Bruunsgaard H, Andersen-Ranberg K, Jeune B, Pedersen AN, Skinhoj P, Pedersen BK. A high plasma concentration of TNFalpha is associated with dementia in centenarians. J Gerontol a Biol Sci med Sci. 1999;54:357-64.

115. Zhao RR, Xu XC, Xu F, Zhang WL, Zhang WL, Liu LM, et al. Metformin protects against seizues, learning and memory impairments and oxidative damage inducet by pentylenetetrazoleinduced kindling in mice. Biochem Biophys Redearch Comm. 2014;4(18):414-7.

116. Oliveira WH, Nunes AK, RochaFrança ME, Santos LA, Bezerra Lós D, Rocha SW, et al. Effects of metformin on inflammation and short-term memory in streptozotocin-induced diabetic mice. Brain res. 2016;1644:149-60.

117. Dai J, Liu M, Ai Q, Lin L, Wud K, Deng X, et al. Involvement of catalase in the protective benefits of metformin in mice with oxidative liver injury. Chemico-Biol. Interact. 2014;216:34-42.

118. Ma J, Yu H, Liu J, Chen Y, Wang Q, Xiang L. Metformin attenuates hyperalgesia and allodynia in rats with painful diabetic neuropathy induced by streptozotocin. Eur. J. Pharm. 2015;764:599606.
119. Khallaghi B, Safarian F, Nasoohi S, Ahmadiani A, Dargahi L. Metformin-induced protection against oxidative stress is associatedwith AKT/mTOR restoration in PG12 cells. Life Scie. 2016;148:286-92.

120. Bonnefont-Rousselot D, Raji B, Walrand S, Gardes-Albert M, Jore D, Legrand A. An intracellular modulation of free radical production could contribute to the beneficial effects of metformin towards oxidative stress. Metabolism. 2003;52:586-9.

121. Ouslimani N, Peynet J, Bonnefont-Rousselot D, Therond P, Legrand A, Beaudeux JL. Metformin decreases intracellular production of reactive oxygen species in aortic endothelial cells. Metabolism. 2005;54:829-34.

122. Batchuluun B, Inoguchi T, Sonoda N, Sasaki S, Inoue T, Fujimura Y, et al. Metformin and liraglutide ameliorate high glucose-induced oxidative stress via inhibition of PKG$\mathrm{NAD}(\mathrm{P}) \mathrm{H}$ oxidase pathway in human aortic endothelial cells. Atherosclerosis. 2014;232:156-64.

123. Sung Moon J, Karunakaran U, Elumalai S, Lee IK, Woo Lee H, Kim YW, et al. Metformin prevents glucotoxicity by alleviating oxidative and ER stress-induced CD36 expression in pancreatic beta cells. J Diab Complic. 2017;31:21-30.

124. Esteghamati A, Eskandari D, Mirmiranpour H, Noshad S, Mousavizadeh M, Hedayati M, et al. Effects of metformin on markers of oxidative stress and antioxidant reserve in patients with newly diagnosed type 2 diabetes: a randomized clinical trial. Clin Nutr. 2013;32:179-85.

125. Mirmiranpour H, Mousavizadeh M, Noshad S, Ghavami M, Ebadi M, Ghasemiesfe M, et al. Comparative effects of pioglitazone and metformin on oxidative stress markers in newly diagnosed type 2 diabetes patients: a randomized clinical trial. J. Diab. Complic. 2013;27:501-7.

126. Chakraborty A, Chowdhury S, Bhattacharyy M. Effect of metformin on oxidative stress, nitrosative stress and inflammatory biomarkers in type 2 diabetes patients. Diabetes res Clin Pract. 2011;93:56-62.

127. Bułdak Ł, Łabuzek K, Bułdak RJ, Kozłowski M, Machnik G, Liber S, et al. Metformin affects macrophages' phenotype and improves the activity of glutathione peroxidase, superoxide dismutase, catalase and decreases malondialdehyde concentration in a partially AMPK-independent manner in LPS-stimulated human monocytes/macrophages. Pharm rep. 2014;66:418-29.

128. Labuzek K, Suchy D, Garbiel B, Bielecka A, Liber S, Okopień B. Quantification of metformin by the HPLC method in brain regions, cerebrospinal fluid and plasma of rats treated with lipopolysaccharide. Pharm. Rep. 2010;62:956-65.

129. Huttunen KM, Mannila A, Laine K, Kemppainen E, Leppänen J, Vepsäläinen J, et al. The first Bioreversible prodrug of metformin with improved lipophilicity and enhanced intestinal absorption. J med Chem. 2009;52:4142-8.

130. Huttunen KM, Leppänen J, Laine K, Vepsäläinen J, Rautio J. Convenient microwave-assisted synthesis of lipophilic sulfonamide prodrugs of metformin. Eur J Pharm Scie. 2013;49:624-8.

131. Rautio J, Vernerová M, Aufderhaar I, Huttunen KM. Glutathione-S-transferase selective release of metformin from its sulfonamide prodrug. Bioorg med Chem Lett. 2016;26(2):35560 .

132. Exalto LG, Whitmer RA, Kappele LJ, Biessels GJ. An update on type 2 diabetes, vascular dementia and Alzheimer's disease. Exp Geront. 2012;47:858-64.

133. Kandimalla R, Thirumala V, Reddy PH. Is Alzheimer's disease a type 3 diabetes? A critical appraisal. Biochim Biophys Acta. 2016;16:S0925-4439. 